\title{
Experimental Analysis of the Performance of a Mechanical Geothermal Water Cooling Tower in South Tunisia
}

\author{
M.T. Chaibi ${ }^{1, *}$, K. Bourouni ${ }^{2}$, M.M. Bassem ${ }^{3}$ \\ ${ }^{1}$ Institut National de Recherche en Génie Rural EauxetForets, Ariana, Tunisia \\ ${ }^{2}$ EcoleNationaled'Ingénieurs de Tunis, LeBelvédère, Tunisia \\ ${ }^{3}$ Centre de Recherche des Technologies de l'Energie de Borj-Cedria, HammamLif, Tunisia \\ *Corresponding author: chaibi.medthameur@iresa.agrinet.tn
}

Received December 20, 2012; Revised February 01, 2013; Accepted February 26, 2013

\begin{abstract}
The paper reports the results of pilot test on the cooling performance of a direct cross flow mechanical cooling tower located in the Kebili region in the southern part of Tunisia. In this study heat and mass transfer data are measured within the tower over a period of one year and compared with external weather data collected over the same period. The data enabled the influence of different weather conditions on the performance of the cooling tower to be analyzed. The results obtained show that ambient humidity has a greater influence on performance than external temperature. In fact, significantly better cooling performance of about $80 \%$ was obtained during the high temperature, low humidity summer months than during the winter period, less than $40 \%$, with relatively low external temperature and high humidity. These results indicate the relative importance of evaporative cooling as compared to convective cooling. The effect of wind on cooling performance was found to be considerable but was confined to those periods when wind direction coincided with the orientation of the louvers of the tower. This was observed to occur only during the summer period when compared to winter period, thus attesting the benefits of the use of proper cooling tower design for improving efficiency and conserve energy.
\end{abstract}

Keywords: mechanical cooling tower, cross flow, cooling efficiency, evaporative cooling, convective cooling, geothermal water, south Tunisia

\section{Introduction}

\subsection{Background}

Geothermal water resources, in the continental Intercallaire CI, extend over an area of $600000 \mathrm{~km}^{2}$ in the region of Algeria, Libya and Tunisia. The small part localized in Tunisia is distinguished by an aquifer of more than $100 \mathrm{~m}$ depth with high pressure of 10 bars and temperature reaching $70^{\circ} \mathrm{C}$. The geothermal water resources have been estimated for $550 \mathrm{Mm}^{3}$ with TDS from 2.5 to $5 \mathrm{~g} / 1$ [1].

The use of geothermal water in Tunisia goes back to ancient times. Originally used for therapeutic purposes, geothermal water is currently used for heating greenhouses and, in the absence of other sources of water, for general agricultural use.

Direct application of geothermal water to crops generally results in extensive damage to foliage. The need to avoid crop damage in areas where high temperature geothermal water is the only practical source of irrigation water has led to the use of cooling towers to lower the temperature of the geothermal water to less than $30^{\circ} \mathrm{C}$ level where it can be applied safely directly onto crops.
Construction of the first generation of cooling towers began in the 1960's with the first unit being built at El Kebayett in south-eastern Tunisia. During the 1980's improved thermal efficiency was achieved through the use of mechanical draft cooling and designs using this method were rapidly adopted (Figure 1). Many of the towers currently operating in the region use the cross flow induced draft system to cool the water.

The main problem with the various types of mechanical draft cooling tower is the cost of the electricity needed to run the cooling process. In consequence, we see from the mid 1990's a new generation of cooling systems being constructed. This new generation seeks to improve energy efficiency by employing a range of different designs such as spiral, cascade, multiple ponds, etc.

The factors affecting the performance of existing cooling towers have been identified on the basis of a number of empirical studies. However, the way in which these factors inter-act to determine the overall performance of the tower is not well understood. In the absence of an adequate model which can be used to represent the operation of a particular design, the performance characteristics of any tower can only be ascertained experimentally with the results being presented in form of correlations [2]. These correlations are function of the inlet and exit air wet bulb temperature and the inlet and exit water temperature. The system can 
also be described in terms of the approach temperature, the temperature range of water and the ratio of the water flow rate and air flow rate [3].

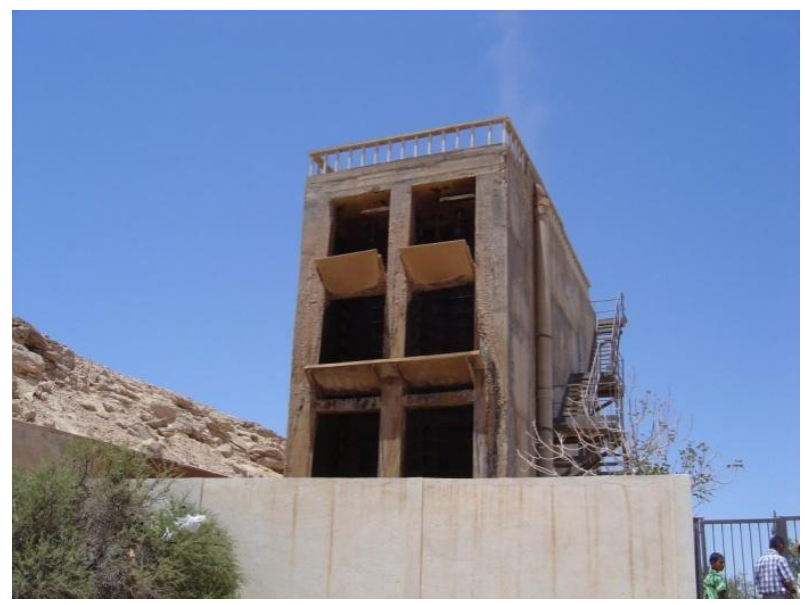

Figure 1. General View of the experimental mechanical draft cooling tower at El Menchia site in Kebili region

The amount of heat that can be removed per unit of cooling tower volume depends on the geometry of the tower, the packing material fill used and the water distribution system. Under certain specific weather conditions the combined effect of the external conditions and the fill geometry of a particular tower may give rise to a loss in performance [4]. Studies indicate that towers may show unexpected sensitivity to external environmental conditions, particularly the speed and direction of the wind [5]. The designs of the cooling towers currently installed in south Tunisia do not allow sufficiently for the impact on tower performance of variations in external weather conditions such as ambient temperature, humidity, wind direction and velocity. Performance is therefore erratic. Hence, the need to investigate the influence of weather conditions on the performance of cooling towers and the importance of identifying appropriate design and construction measures which can maximize the performance of designs currently in use.

\subsection{Literature Review}

Several authors in the field of cooling towers dedicated their researches to the development of cooling systems performance. Soylemez [6] studied the performance of cooling towers considering the thermo-hydraulic aspects of the cooling devise. He developed a general mathematic model where the optimal ratio of water and air flow in order to maximize efficiency of the cooling system was determined. Al-Nimr [7] presented a simple mathematic model to describe the thermodynamic performance of a counter flow induced draft cooling towers, allowing the determination of the height of the tower in which the water and air temperature reach the same value. Khan et al. [8] developed serious analysis of the clogging phenomena including the effect of fouling on system cooling efficiency. Sutherland [9] presented the pressure effect on thermal performance of the cooling system, and showed that air temperature and humidity have a significant effect on cooling tower performance. Merkel [10], Sutherland [9], Poppe and Rogener [11] and Haszler [12] developed the principles of mathematical equations of thermal and mass exchanges using different values of Lewis number describing evaporative cooling processes. Khan et al. [13] presented the performance characteristics of the cooling tower using the same hypothesis presented by Khan et al. [13]. Dreyer and Erens [14] developed a mathematical model for the modeling of counter flow cooling tower splash pack thermal performance allowing predicting the correct trends for both the transfer characteristics and the pressure drop across the packing material. Al-Sulaiman [15] evaluated the performance of palm fibers (stem), jute and luffa to be used as wetted pads in evaporative cooling including cooling efficiency, material performance and cooling efficiency degradation. Seetharamu and Swaroop [16] have studied the performance of smaller sized fluidized-bed cooling towers and Sisupalan and Seetharamu [17] have examined the performance variation of a fluidized-bed cooling tower for different static bed heights.

Some studies have been performed in the areas where weather conditions are affective on the cooling efficiency of dry cooling towers [18,19], however, a very few of them incorporate experimental studies on cooling process using palm trees as packing material. The available literature shows a lack of experimental data in this particularly type of towers, widely used in Tunisia.

\subsection{Objectives}

This paper derives from a twelve month study of the performance of one cooling tower located in the south of Tunisia. The aim of the study has been to determine experimentally the effect of the inter-action of external weather parameters and the thermal characteristics of the tower on cooling performance. The subject - a mechanical geothermal water cooling tower- was chosen in view of the widespread use of this design in Southern Tunisia and in view of the need to increase cooling efficiency and to reduce energy consumption to remain competitive with more modern systems.

\section{Materials and Methods}

\subsection{Experimental Plant}

Experiments were carried out on the flow-induced draught cooling tower of "El Menchia" located in Kebili at the Southern part of Tunisia (latitude N $33^{\circ} 42^{\prime} 7^{\prime}$ ', longitude E $8^{\circ} 58^{\prime} 25^{\prime \prime}$ ' and altitude $34 \mathrm{mvh}$ ). A schematic of the pilot cooling tower is shown in Figure 2.

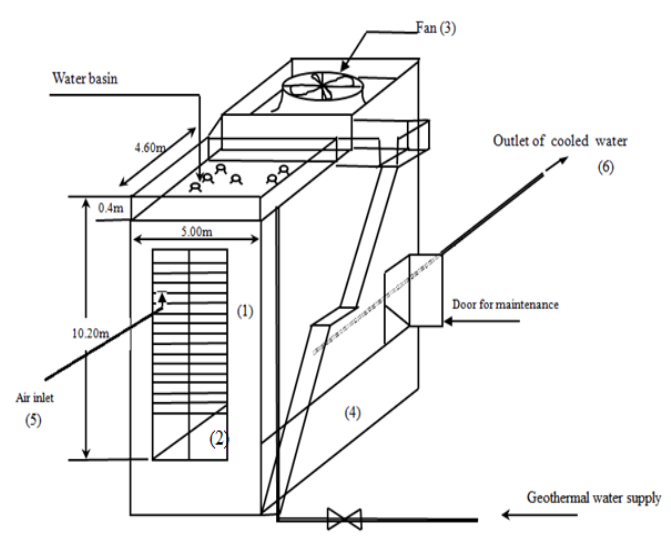

Figure 2. Schematic of the pilot cooling tower 
The pilot tower is equipped with filling (1), a droplet separator (2) and a water distribution system. It also equipped with a fan (3) at the top exit of the tower and a concrete bottom basin (4) for collecting cooled water.

The fill packing material is composed of palm trees installed at the same level as the air intake (5). Atmospheric air is drawn by the fan from side louvers and moves horizontally through the fill. Geothermal water is evenly sprayed from and falls down into the water basin. Air from the exterior is drawn across the fill and comes in contact with the water film. The evaporation of a small portion of the geothermal water causes the temperature of the remaining water to decrease as it moves through the fill generating a counter-current to the extracted air. The water vapour from the evaporation is absorbed by the air stream and exits through the exit at the top of the tower. Large water droplets carried in the air stream are collected by the drift eliminators. The cooled water falls into the water basin and flows to canals (6) to be used for irrigation purposes.

\subsection{Experimental Measurement}

\subsubsection{Air Parameters}

The temperature profile of air extracted by the fan was measured using temperatures probes (type PRT $100 \mathrm{ohms}$ ) at three levels across the cooling tower aspiration chamber: at the bottom, middle and top exit of the fan (Figure 3 and Figure 4). The humidity of the extracted air was also measured at a single point, $1.5 \mathrm{~m}$ above the fan.

\subsubsection{Water Parameters}

The temperature profile of the geothermal water was measured at six equidistant levels along the vertical axis of the tower using probes (type PRT 100 ohms) placed at thirty points (Figure 4). Five probes were fixed at each level; three in the middle with two probes being mounted alternately on the extreme left or right side of the tower (Figure 3 and Figure 4). The arrangement of the probes was designed to enable the water temperature profile over the entire inner volume of the tower to be measured. In addition, the inlet and outlet geothermal water temperature and the temperature of the collected condensed water vapor were also measured using the same type of probe.

\subsubsection{Climate Parameters}

The parameters measured and the instruments used were as follows:

-Air temperature and humidity using an AM100A temperature and relative humidity probe developed by Rotronic, for continuous temperature and humidity recording.

-Wind velocity-Wing Anemometer (type Vector A100 with 6 cups)

-Wind direction-Potentiometer Windvane (type W200P)

-Global solar irradiation in the horizontal plane

-Pyranometers (type Kipp and Zonen thermopile pyranometers CM11)

These sensors were integrated in a single meteo station located at the side of the experimental cooling tower (Figure 2). Sensors were individually calibrated and connected to a computer controlled data acquisition system.
Data was collected at 15 minute intervals over one year (2005) with the exception of March, April and May when water parameters were not recorded due to the breakdown of the data logger machine.

The results of the study use data relating to a 'typical day' of each month. The typical day of any given month is the one where average temperature and humidity values for the ambient air most closely approach the average values provided by the national weather report for these variables over the last ten years.

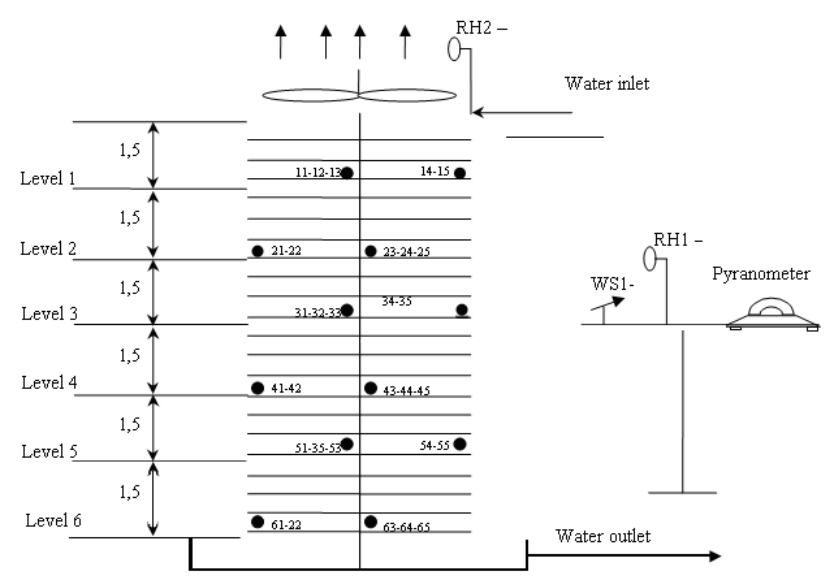

Figure 3. Vertical cross section of the experimental cooling tower, to scale (width $4.60 \mathrm{~m}$, length $5.00 \mathrm{~m}$, height $10.20 \mathrm{~m}$ ); position of the fill packing material is indicated with dotted line.

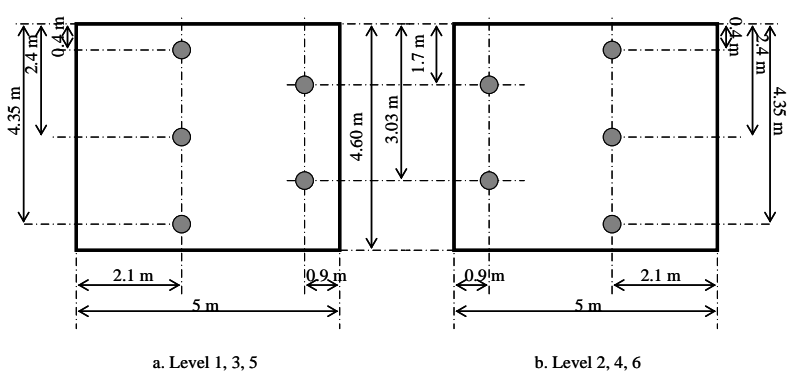

Figure 4. Location of thermocouples in the different levels of the cooling tower (Upper view)

\section{Results and Discussion}

\subsection{Water Temperature Distribution inside the Cooling Tower}

Figure 5 shows clearly the interaction of tower design and orientation with weather parameters on the water temperature distribution in this cooling tower. This Figure shows the vertical profiles in the mid-plane of the cooling tower (i.e. their average horizontal component) for two different typical day climate conditions one in summer, the other in winter period.

During both climate conditions, isotherms show thin boundary layers in the top cooling tower between 9 and $10 \mathrm{~m}$ height with gradual stratification over the core of the tower. The cooling efficiency proved to be very low due to the reduced air flow circulation through the top area of the tower. This has been confirmed by the horizontal isotherms that move downward at a constant temperature of a range between 70 and $56^{\circ} \mathrm{C}$. 
During the typical day of the summer season, direct observations of the thermal distribution within the core of the tower show that within this region of the most steeply sloping isotherms, from about 50 to $28^{\circ} \mathrm{C}$ in the last $1.1 \mathrm{~m}$ above the bottom tower surface, considerable gradual stratification is present and water temperature tend to be lower at the air inlet $(\mathrm{x}=0)$ rather than the one at the air outlet $(x=4 m)$. Figure 2 illustrates this situation.

This gradient, along the $\mathrm{x}$-axis, is proved by the presence of a dry air flow heated and humidified up progressively along its path horizontally through the tower, decreasing the temperature difference between water and the moving air and increasing air humidity (Figure 5 (a)).

The same vertical temperature profiles in the mid-plane of the cooling tower on a typical day in winter are shown in Figure 5 (b). These profiles are characterized by gradual and slow decrease in water temperature by about $17^{\circ} \mathrm{C}$ in the first $2.9 \mathrm{~m}$ beneath the top of the tower and a single rotating loop with significant water temperature decrease along the side louvers of the tower reaching $45.2^{\circ} \mathrm{C}$, while the core temperature of the tower remains rather high.

The high humidity, characterizing the weather conditions in winter season, has been found to affect the efficiency of the evaporative cooling system.

Considering the relation between the evaporative and convective mechanisms in the overall water cooling process, the dominance of the evaporative transfer potential comparing to the convective one can be clearly observed. This is confirmed by the fact that the ambient air flow through the fan is characterized by high humidity with low temperature during winter climate conditions. This result confirms the one obtained in the previous theoretical analysis of the same tower developed by Bourouni et al. [20] stating that the evaporative potential is dominating the convective one in the cooling process. The obtained results of this case study are in good agreement with those found in the literature particularly the one found by Stranford [21] who reported that more than two thirds of transferred heat lost during cooling is due to evaporation with the remainder being transferred by convection.

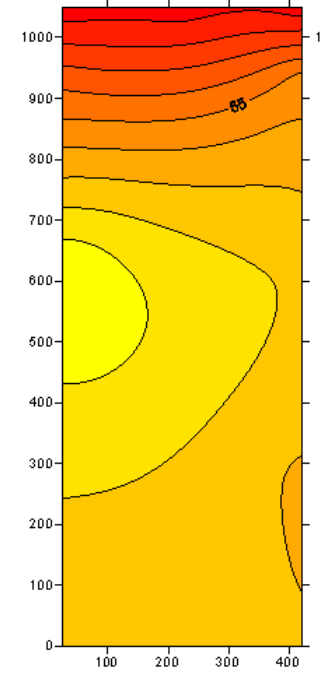

(a)

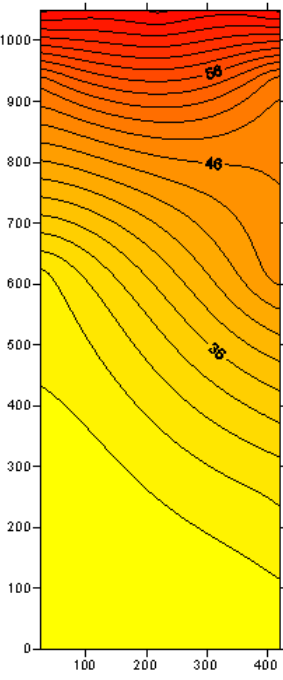

(b)
Figure 5. Vertical water temperature patterns obtained from thermocouples (temperature intervals between successive isotherms, $2^{\circ} \mathrm{C}$ ) in the mid plane of the cooling tower during: (a) typical day of June, (b) typical day of February

\subsection{Sensitivity Analysis of the Tower Efficiency to Variations in Climate Conditions}

The efficiency of a cooling tower is defined as the actual difference in water temperature between the inlet and the outlet of the tower divided by the maximum value this difference could reach. Since water temperature cannot be lower than the wet bulb temperature of air, the maximum difference is therefore equal to the difference between the water temperature at the inlet of the tower and the wet bulb temperature of air. The efficiency of the cooling tower can be calculated using the following equation:

$$
\eta=\frac{T_{w, \text { in }}-T_{w, \text { out }}}{T_{w, \text { in }}-T_{a, b}}
$$

Where $\eta$ is the cooling efficiency, $T_{w, \text { in }}$ and $T_{w, \text { out }}$ are the inlet and outlet temperatures of geothermal water, and $\mathrm{T}_{\mathrm{a}, \mathrm{b}}$ is the wet bulb temperature of the ambient air stream.

\subsubsection{Influence of the Ambient Air Temperature and Humidity}

The cooling tower efficiency $(\eta)$ is calculated during typical days of the different months of the year, and the obtained results are presented in Figure 6. This figure shows that the efficiency increases significantly from winter (cold period) to summer season (hot period) then decreases during autumn period, characterized by mild weather conditions (September-December). During winter period, the efficiency reaches its lowest values, of less than $30 \%$, comparing to summer season where the efficiency of the cooling tower exceeds $80 \%$. The variations of the climate conditions ( $\varphi$ and $\mathrm{T}_{\mathrm{a} . \mathrm{d}}$ ) during the year are considered in Figure 7 (a) and (b) in order to explain this finding.

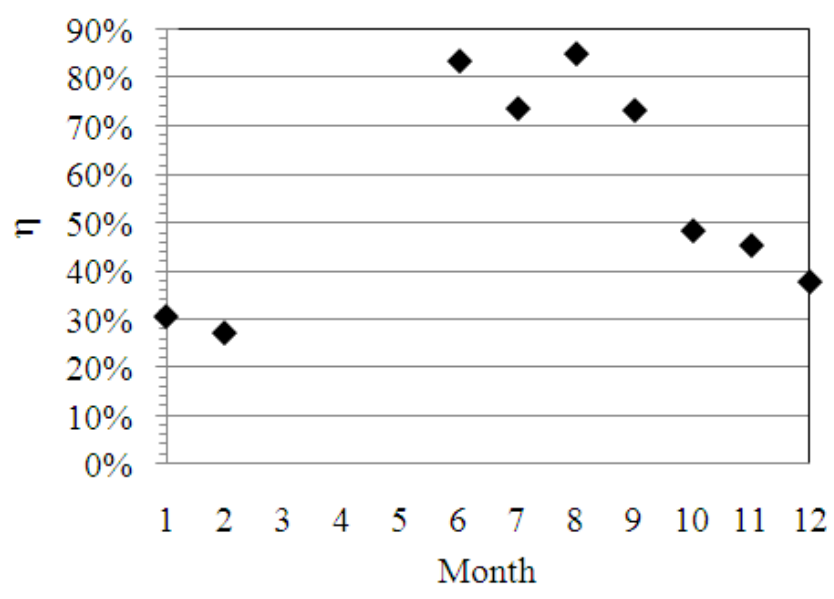

Figure 6. Variation of the cooling tower efficiency $(\eta)$ during the year

Figure 7 (a) shows that; the dry air temperature has the same trend with the cooling tower efficiency. This means that higher values of $\eta$ are obtained when $T_{a . d}$ increases. On the other hand, the increase of $\mathrm{T}_{\mathrm{a} . \mathrm{d}}$ induces to $\mathrm{a}$ decrease of the convective heat transfer in the cooling tower and an increase of air capacity to convey water vapor by the evaporation process. 
Figure 7 (b) shows that the air relative humidity, $\varphi$, reaches the highest value during winter period (higher than $70 \%$ ) and decreases during the summer to an average value of about $55 \%$. This result confirms the previous conclusion that dry ambient air with a low humidity has a higher capacity to evaporate water than when it is humid.

Hence, the influence of both dry air temperature and humidity on the efficiency of the cooling tower shows that the convective potential is not the predominant phenomenon during the cooling process and suggests strongly that the cooling should be performed mainly by the evaporation process.

This result was also highlighted by Bourouni et al. [20] based on numerical investigation. The authors have developed a mathematical model to simulate heat and mass transfer in all the parts of the cooling tower. It was noticed that at a certain height of the cooling tower, the air temperature was decreasing to become lower than the water temperature. This behavior shows that the negative convection is occurring, and the water cooling is performed by evaporation and, consequently, the water and air are cooled simultaneously.

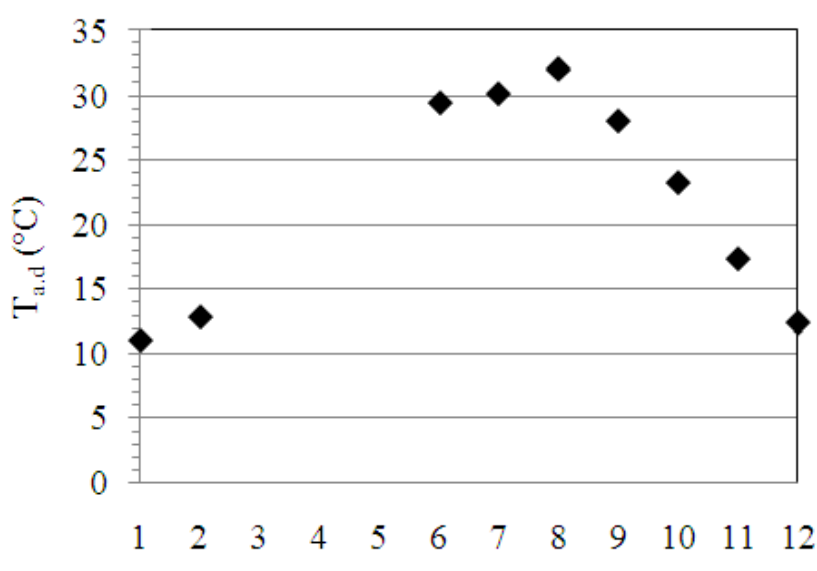

(a) Month

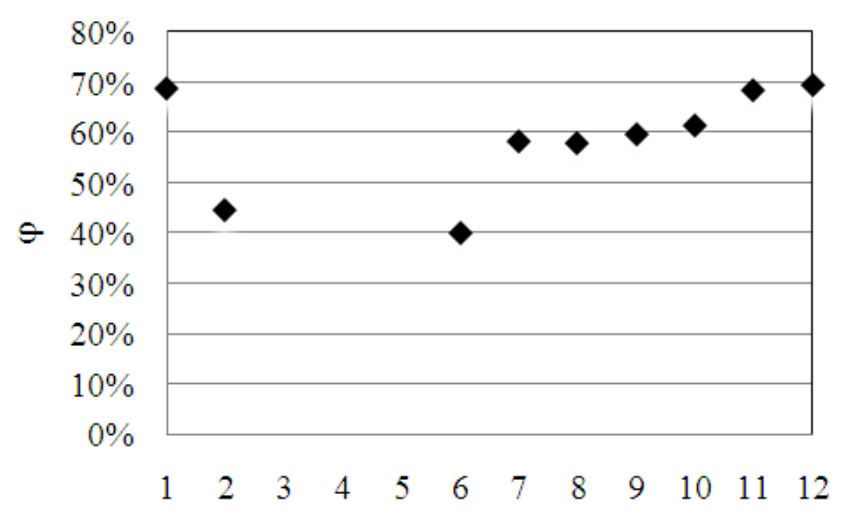

(b) Month

Figure 7. Variation of the local climate conditions during the year: (a) dry air temperature $(\mathrm{T}$ a,d), (b) air relative humidity $(\varphi)$

\subsubsection{Influence of Wind Direction and Speed on Cooling Tower Performances}

The effects of the speed and direction of the wind on the efficiency of the cooling tower are illustrated in Figure 8. This data has been obtained when the fan has been working during the month of July. It will be recalled that ambient air is introduced to the tower through louvers oriented toward the Northeast.

According to Figure 8, it can be seen that an effect of wind speed on cooling can be observed only when the direction of the wind coincides with the orientation of the louvers of the tower (Northeast). In fact, under strong wind conditions, defined as wind speed more than $4 \mathrm{~m} \mathrm{~s}^{-1}$, for which wind direction favored air circulation inside the cooling tower, efficiency is highest considering the low level of the average water temperature at the exit of the tower of about $35^{\circ} \mathrm{C}$. There was a sharp decrease of the efficiency with decreasing wind speed lower than $4 \mathrm{~m} \mathrm{~s}^{-1}$, giving an average of water temperature at the exit varying of $47^{\circ} \mathrm{C}$ and $50^{\circ} \mathrm{C}$.

In the case where wind direction doesn't coincide with the orientation of the louvers no or little effect of wind speed on the efficiency of cooling is observed. Thus, for the different wind speed conditions, the observed water temperature at the exit of the tower ranged from 50 to $55^{\circ} \mathrm{C}$.

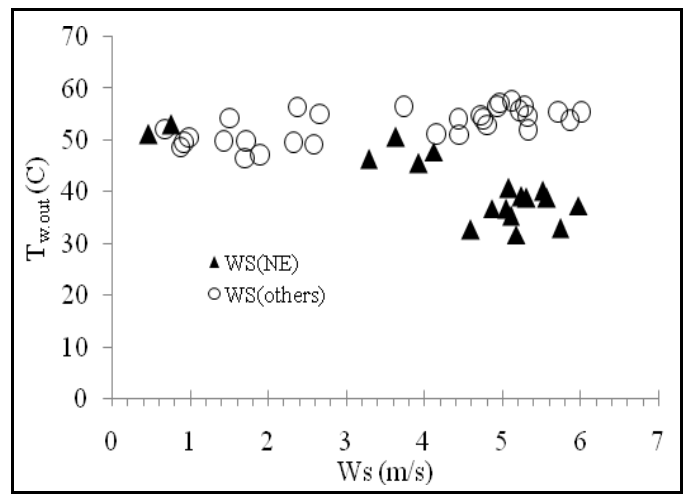

Figure 8. Influence of the wind speed on water outlet temperature during summer period

These results allow an important conclusion can be drawn: that if the wind direction coincides with the orientation of the louvers and if the wind speed is considerable (higher than $4 \mathrm{~m} / \mathrm{s}$ ) acceptable temperatures of water can be reached without the use of an electric fan.

The effects of the speed and direction of wind on the efficiency of cooling during winter period are illustrated in Figure 9. The experimental values were obtained while the fan was not working during February. Figure 9 shows that during the winter period, neither the speed nor the direction of wind has any significant effect on cooling efficiency. This is due to the very high humidity of the ambient air during this period.

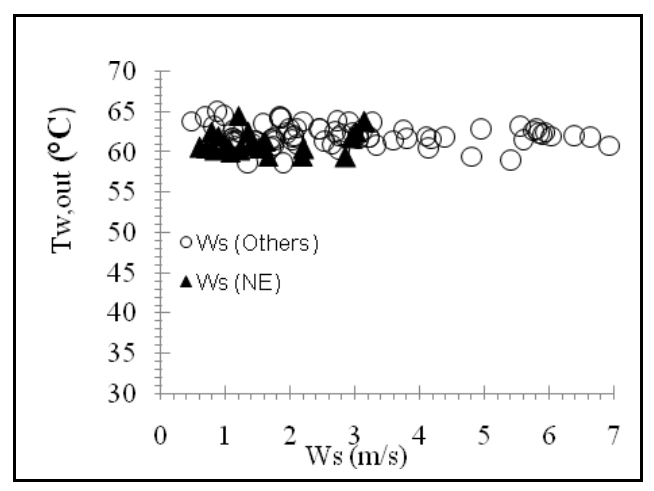

Figure 9. Influence of wind speed on water outlet temperature of the cooling during winter period 


\section{Conclusions}

In the present paper, experiments were conducted to determine the effect of the inter-connection of the external weather parameters and the thermal characteristics of a mechanical geothermal water cooling tower because no similar detailed investigations were carried out, in view of the need to increase cooling efficiency and to reduce energy.

It is concluded that higher cooling efficiency is obtained during summer period, characterized by high temperature and low humidity of the ambient air, due to the predominant factor in the cooling process performed essentially by evaporation.

These results and analysis is valuable for the cooling tower designers or manufacturers in providing an effective control of the output temperature, and the regulatory authority on geothermal water use for irrigation should enforce a more reasonable specification for minimum tower efficiency. It is hoped that the development of this specification, considering the wind direction and the climate directions of the region, will form the driving force to make the operation of water cooled tower more efficient and sustainable.

\section{Acknowledgement}

This work was supported by a grant of the Tunisian Ministry of High Education and Scientific Research. We would like to thank the Regional Agricultural Development Commission of Kebili and Mr. Crasner for their support in the development and producing this work. Also my thanks go to Mr. Naffati and late Mr. Fitouri for their assistance in setting up and conducting the experiments.

\section{Nomenclature}

T temperature $\left({ }^{\circ} \mathrm{C}\right)$
Ws wind speed $(\mathrm{m} / \mathrm{s})$
Greeks:
$\mathrm{X} \quad$ relative humidity of ambient air $(\%)$
$\eta \quad$ efficiency
Subscripts:
a air
b wet bulb
in inlet
out outlet
w water

\section{References}

[1] H. Zebidi, Explanatory note of the Tunisian water resources map (French), Publication of the general Directorate of Water Resources, 25pp, 1991.

[2] N.P. Cheremisinoff, P.N. Cheremisinoff, Cooling towers: Selection, Design and Practice, Ann Arbor Science Publishers, Michigan, 1983.

[3] A.K.M. Mohiuddin, K. Kant, Knowledge base for the systematic design of cooling towers (Part I): Selection and tower characteristics, International Journal of Refrigeration, 19(1): 4351, 1996.

[4] A.P. Fraas, Heat Exchanger Design, John Wiley \& Sons, 383-401, 1988.

[5] E. Ding, (Ed.), Air Cooling Techniques in Power Plants, Water and Electric Power Press, Beijing 1992.

[6] M.S. Soylemez,On the optimum performance of forced draft counter flow cooling towers, Energy Conversation and Management. 45: 2335-2341, 2004.

[7] M. Al Nimr, Dynamic thermal behaviour of cooling towers, Energy Conversation Management. 39: 631-636, 1998.

[8] J.R. Khan, B.A. Qureshi, S. Zubair, A comprehensive design and performance evaluation study of counter flow wet cooling towers, International Journal of refrigeration 27: 914-923, 2004.

[9] J.M. Sutherland, Analysis of mechanical draught counter flow air/water cooling towers, ASME Journal of Heat Transfer 105: 576-583, 1983.

[10] F. Merkel, Evaporative cooling, Journal of German Engineers, VDI (German), 70: 123-128, 1925.

[11] M. Poppe, H. Rogener, Calculation of cooling tower, VDI-Heat Atlas (German), 37:1-15, 1991.

[12] R. Haszler, Influence of condensation in the boundary layer on the heat and mass transfer in a falling film, progress report (German), 38: 134-141, 1994.

[13] J.R.Khan, M. Yaqub, S.M. Zubair, Performance characteristics of counter flow wet cooling towers, Energy Conversation and Management. 44(13): 2073-2091, 2003.

[14] A.A. Dreyer, P.J. Erens, Modeling of cooling tower splash pack. International Journal of Heat Mass Transfer. 39: 109-123, 1996.

[15] F. Al-Sulaiman, Evaluation of the performance of local fibers in evaporative cooling, Energy Conversion and Management. 43(16) 2267-2273, 2002.

[16] K.N. Seetharamu, S. Swaroop, The effect of size on the performance of a fluidized bed cooling tower, Heat and Mass Transfer. 26(1): 17-21, 1991.

[17] N. Sisupalan, K. N. Seetharamu, Heat transfer and pressure drop in fluidized bed cooling tower, Heat and Mass Transfer. 27(8): 499-503, 1992.

[18] Q. Wei, K. Zhang, K. Liu, X. Du, A study of the unfavorable effects of wind on the cooling efficiency of dry cooling towers, Journal of Wind Engineering and Industrial Aerodynamics 54: 633-643, 1995.

[19] M.D. Su, G.F. Tang, S. Fu, Numerical simulation of fluid flow and thermal performance of a dry-cooling tower under cross wind condition, Journal of Wind Engineering and Industrial Aerodynamics 79(3): 289-306, 1999.

[20] K. Bourouni, M. Bassam, M.T. Chaibi, Numerical Study of Coupled Heat and Mass Transfer in a Geothermal Water Cooling Tower, Energy Conservation and Management 49(5): 988-994, 2008.

[21] W. Stanford, Cooling towers -principles and practice, 2nd ed, Carter Industrial Products, 1972. 